\title{
Arterial stiffness is increased in asthmatic children
}

\author{
Markus Steinmann • Chiara Abbas • Florian Singer • \\ Carmen Casaulta $\cdot$ Nicolas Regamey $\cdot$ Dieter Haffner • \\ Dagmar-Christiane Fischer • Giacomo D. Simonetti
}

Received: 11 July 2014 /Revised: 7 September 2014 / Accepted: 10 September 2014 /Published online: 25 September 2014

(C) Springer-Verlag Berlin Heidelberg 2014

\begin{abstract}
Altered arterial stiffness is a recognized risk factor of poor cardiovascular health. Chronic inflammation may increase arterial stiffness. We tested whether arterial stiffness is increased children with asthma, a chronic disease characterized by fluctuating airway and systemic inflammation. Arterial stiffness, expressed as carotid-femoral pulse wave velocity $\left(\mathrm{PWV}_{\mathrm{cf}}\right)$, was measured in 37 mild-to-moderate asthmatic children: 11 girls, median (range) age 11.1 years (6-15). $\mathrm{PWV}_{\mathrm{cf}}$ in asthma was compared to $\mathrm{PWV}_{\mathrm{cf}}$ in 65 healthy controls matched for age, height, and gender previously studied in Germany and was correlated with airway inflammation and obstruction. $\mathrm{PWV}_{\mathrm{cf}}$ was higher in asthmatic children compared to controls: $\mathrm{PWV}_{\mathrm{cf}}$ median (interquartile range) was $4.7 \mathrm{~m} / \mathrm{s}(4.5-4.9)$ vs. $4.3 \mathrm{~m} / \mathrm{s}(4.1-4.7), p<0.0001$. In asthmatic children, $\mathrm{PWV}_{\mathrm{cf}}$ was inversely associated $\left(r^{2}=0.20\right.$, $p=0.004)$ with forced expiratory volume in $1 \mathrm{~s}\left(\mathrm{FEV}_{1}\right)$. This association remained significant after adjusting for possible
\end{abstract}

Communicated by Peter de Winter

M. Steinmann • G. D. Simonetti $(\bowtie)$

Division of Pediatric Nephrology, Department of Pediatrics,

Inselspital, Bern University Hospital, and University of Bern,

3010 Bern, Switzerland

e-mail: Giacomo.Simonetti@insel.ch

M. Steinmann

e-mail: markustimosteinmann@gmail.com

M. Steinmann $\cdot$ C. Abbas $\cdot$ F. Singer $\cdot$ C. Casaulta $\cdot$ N. Regamey Division of Pediatric Respiratory Medicine, Department of Pediatrics, Inselspital, Bern University Hospital, and University of Bern, Bern, Switzerland

C. Abbas

e-mail: Chiara.Abbas@insel.ch

F. Singer

e-mail: florian.singer@kispi.uzh.ch

C. Casaulta

e-mail: Carmen.Casaulta@insel.ch confounders including body mass index, blood pressure, steroid use, and FeNO.

Conclusion: Arterial stiffness is increased in children with mild-to-moderate asthma. The association between impaired lung function and increased arterial stiffness suggests that severity of disease translates into detrimental effects on the cardiovascular system.

Keywords Arterial stiffness · Asthma $\cdot$ Children $\cdot$ Pulse wave velocity $\cdot$ Inflammation

\section{Introduction}

Carotid-femoral pulse wave velocity $\left(\mathrm{PWV}_{\mathrm{cf}}\right)$ is an established marker of arterial stiffness with the latter being a recognized predictor of poor cardiovascular health [13].

\footnotetext{
N. Regamey

e-mail: Nicolas.Regamey@bluewin.ch

F. Singer

University Children's Hospital Zurich, Steinwiesstrasse 75, 8032 Zurich, Switzerland

D. Haffner

Department of Pediatric Kidney, Liver and Metabolic Disease,

Hannover Medical School, Hannover, Germany

e-mail: haffner.dieter@mh-hannover.de

D.-C. Fischer

Department of Pediatrics, University Hospital Rostock, Rostock, Germany

e-mail: dagmar-christiane.fischer@med.uni-rostock.de

G. D. Simonetti

Pediatric Department of Southern Switzerland, Bellinzona,

Switzerland
} 
Increasing evidence suggests that chronic inflammation increases arterial stiffness and subsequently modulate cardiovascular morbidity $[12,13,18]$. Indeed, arterial stiffness has been shown to be elevated in chronic inflammatory diseases like rheumatoid arthritis, Kawasaki disease, chronic renal failure, inflammatory bowel diseases, and acute glomerulonephritis $[3,5,7,22,23]$. Currently, few data exist about alterations of arterial stiffness in children with chronic inflammatory diseases, although atherosclerosis may originate in childhood [17, 19]. Chronic obstructive pulmonary diseases has been related to an increased incidence of cardiovascular diseases in adults, even after correction for the effects of established cardiovascular risk factors, particularly smoking [16].

In this cross-sectional study, we tested the hypothesis that arterial stiffness is increased in school-age children with asthma, a chronic disease characterized by fluctuating airway and systemic inflammation [1]. Studying children has the great advantage that (physiological) effects of aging, and the integrated time of exposure to smoke are almost neglectable. Secondary aims were to relate arterial stiffness to airway inflammation and obstruction in asthma.

\section{Materials and methods}

\section{Patients}

$\mathrm{PWV}_{\mathrm{cf}}$ as a surrogate marker of arterial stiffness was measured in asthmatic school-age children during routine follow-up in the outpatient clinic of a tertiary care center (Bern University Hospital, Switzerland). Asthma was diagnosed according to standard criteria [1]. Exclusion criteria were the presence of other significant diseases, e.g., abnormalities of the cardiovascular system and/or limbs (the latter would make the measurement of arterial stiffness impossible) and preterm birth $(<37$ weeks of gestation). Children were instructed not to inhale bronchodilators at least $12 \mathrm{~h}$ before the study. The control group consisted of age-, height-, and gender-matched healthy subjects studied in Germany who were described elsewhere [10]. Control children were not evaluated for subclinical signs and symptoms of asthma. Children born preterm were not excluded in the control group.

The local research ethics committee approved the study, and informed consent was obtained from all parents and children.

\section{Measurements}

Clinical and anthropometric data including height, weight, body mass index (BMI), puberty stage (Tanner stages), and blood pressure were recorded. The pulse wave velocity between the carotid and femoral artery $\left(\mathrm{PWV}_{\mathrm{cf}}\right)$ was measured by means of the validated Vicorder ${ }^{\mathrm{TM}}$ device (Skidmore Medical Limited, Bristol, UK), as previously reported in detail [10]. For calculation of $\mathrm{PWV}_{\mathrm{cf}}$, the corrected distance between the midpoints of the oscillometric cuffs placed over the carotid and femoral arteries was divided by the automatically recorded transit time (time lag between pulse wave registration at the carotid and femoral cuffs) as described elsewhere [10, 20]. To account for the differences between the tape measured distance between both cuffs and the reference distance, a correction factor of 0.8 was used $[10,20]$. The same protocol for determination of $\mathrm{PWV}_{\mathrm{cf}}$ was used throughout the study. The same investigator (MS) performed three $\mathrm{PWV}_{\mathrm{cf}}$ measurements in each asthmatic child, and the mean $\mathrm{PWV}_{\mathrm{cf}}$ of these measurements was taken as the primary outcome. Standard deviation score (SDS) of $\mathrm{PWV}_{\mathrm{cf}}$ accounting for height and gender were computed from published pediatric reference values. These data were obtained using the same device and measurement protocol to derive a set of age- (or height-) and sex-specific data (least mean square (LMS) values) [10], which were modeled using the modified LMS method of Cole and Green [6].

Spirometry (Jaeger MasterScreen ${ }^{\circledR}$ bodyplethysmograph, Wuerzburg, Germany) was performed according to current recommendations. Spirometry outcomes were forced expiratory volume in $1 \mathrm{~s}\left(\mathrm{FEV}_{1}\right)$ and forced expiratory flow between $25-75 \%$ of the expired volume $\left(\mathrm{FEF}_{25-75}\right)$ reported as liter or liter per second and SDS [15]. In children with significant airway obstruction ( $\mathrm{FEV}_{1}$ or $\mathrm{FEF}_{25-75}<-1 \mathrm{SDS}$ ), $\mathrm{PWV}_{\mathrm{cf}}$ was measured before and after the inhalation of $0.4 \mathrm{mg}$ salbutamol to examine a possible effect of beta-2-agonists on arterial stiffness. The fraction of exhaled nitric oxide (FeNO) was measured after spirometry with a chemiluminescence analyzer (CLD 88 sp $^{\circledR}$; Eco Medics AG, Duernten, Switzerland). FeNO values of more than 35 parts per billion (ppb) in children aged $\leq 12$ years, and more than $50 \mathrm{ppb}$ in older children were considered to indicate relevant eosinophilic airway inflammation [8].

\section{Statistical analysis}

Power calculation was performed to determine sample size. At least 26 children are needed to achieve a study power of $80 \%$, with an error $=0.05$, estimating a potential difference between the two groups of $0.4 \mathrm{~m} / \mathrm{s}$ and a standard deviation of $0.5 \mathrm{~m} / \mathrm{s}$ $\mathrm{PWV}_{\mathrm{cf}}$.

Data are presented as median and interquartile range (IQR) as appropriate. Normally, distributed data were compared by $t$ test and nonparametric data by Mann-Whitney $U$ test. Correlations were graphically assessed, and a forward stepwise multivariable linear regression analysis was applied to identify 
significant independent factors explaining $\mathrm{PWV}_{\mathrm{cf}}$ variability in this population. $p$ values $<0.05$ were regarded as significant.

\section{Results}

Thirty-seven asthmatic children (11 girls (30\%) and 26 boys (70\%), median age 11.1 years, range $6.1-15.3$ years, Table 1 ) were included in the study together with 65 healthy children (20 girls ( $31 \%$ ) and 45 boys ( $69 \%$ ), median age 10.9 years, range $6-15.4$ years, Table 1$)$. One child (3\%) in the asthma group and three children (5\%) in the control group were obese (i.e., BMI SDS $>1.88$ ). $\mathrm{FEV}_{1}$ and $\mathrm{FEF}_{25-75}<-1$ SDS were observed in $14(38 \%)$ and $16(43 \%)$ asthmatic children, respectively, and 11 children (30\%) had increased FeNO. Three children $(8 \%)$ had $\mathrm{FEV}_{1}<-2$ SDS and four children (11\%) $\mathrm{FEF}_{25-75}<-2$ SDS. Nine children ( $24 \%$, three girls) had puberty Tanner stage $\geq 3$. Twenty-nine children (78 \%) received low-to-moderate dosages of inhaled steroids $(<800$ ug budenoside equivalent) as maintenance therapy. Age, puberty stage, weight, height, BMI, steroid use, $\mathrm{FEV}_{1}$, $\mathrm{FEF}_{25-75}, \mathrm{FeNO}$, and $\mathrm{PWV}_{\text {cf }}$ SDS were similar in asthmatic boys and girls (data not shown).

$\mathrm{PWV}_{\text {cf }}$ was higher in asthmatic children compared to the control group: median (IQR) $4.7 \mathrm{~m} / \mathrm{s}(4.5-4.9)$ vs. $4.3 \mathrm{~m} / \mathrm{s}$ (4.1-4.7); $p<0.001$. $\mathrm{PWV}_{\mathrm{cf}}$ was higher in asthmatic children in all ages (Fig. 1). There was no difference in $\mathrm{PWV}_{\mathrm{cf}}$ between asthmatic children with and without increased FeNO. In children with more pronounced airway obstruction $(n=20(54 \%)$; $\mathrm{FEV}_{1}$ or $\left.\mathrm{FEF}_{25-75}<-1 \mathrm{SDS}\right), \mathrm{PWV}_{\mathrm{cf}}$ measured before and after bronchodilation was almost identical: median $4.7 \mathrm{~m} / \mathrm{s}$ (4.5-4.9) vs. $4.8 \mathrm{~m} / \mathrm{s}$ (4.6-5.0); $p=$ ns. Eight (22\%) asthmatic children had $\mathrm{PWV}_{\mathrm{cf}}$ values above the 95 centile corrected for gender and height. No significant differences in lung function parameters were noted in these children compared to the asthmatic children with $\mathrm{PWV}_{\mathrm{cf}}$ within the normal range.

$\mathrm{PWV}_{\mathrm{cf}}$ SDS was inversely related to $\mathrm{FEV}_{1}$ and $\mathrm{FEF}_{25-75}$ (linear regressions $r^{2}=0.20, p=0.004$ and $r^{2}=0.11, p=0.03$, respectively) but not to FeNO or steroid use. Also in the subgroup of asthmatic children without steroid treatment $(n=8)$, there was no correlation between FeNO and PWV. $\mathrm{FEV}_{1}$ remained significantly associated with $\mathrm{PWV}_{\mathrm{cf}} \mathrm{SDS}$ in a forward stepwise multivariate linear regression analysis $\left(r^{2}=\right.$ $0.23, p=0.004$ ) adjusting for possible confounders including BMI SDS, systolic and diastolic blood pressure SDS, steroid use, and FeNO.

\section{Discussion}

Arterial stiffness, measured as $\mathrm{PWV}_{\mathrm{cf}}$, is increased in schoolage children with mild-to-moderate asthma. About $20 \%$ of asthmatic children have a pathologically increased arterial stiffness (PWVcf values above the 95 centile corrected for gender and height). This indicates that asthma affects the

Table 1 Characteristics of school-aged children with asthma and healthy age-, height-, and gender-matched controls

\begin{tabular}{|c|c|c|c|}
\hline Characteristics & Asthma children $(n=37)$ & Control group $(n=65)$ & $p$ \\
\hline Body height (m) & $1.45(1.32$ to 1.58$)$ & $1.44(1.31$ to 1.58$)$ & 0.90 \\
\hline Body height SDS & $0.3(-0.1$ to 0.91$)$ & $0.1(-0.6$ to 0.6$)$ & 0.06 \\
\hline Body weight (kg) & $40.2(26.5$ to 48.6$)$ & 34.4 (28.0 to 46.2$)$ & 0.56 \\
\hline Body weight SDS & $0.1(-0.4$ to 0.8$)$ & $-0.2(-0.8$ to 0.7$)$ & 0.08 \\
\hline Body mass index $\left(\mathrm{kg} / \mathrm{m}^{2}\right)$ & $17.7(15.6$ to 20.0$)$ & $17.2(15.5$ to 19.4$)$ & 0.50 \\
\hline Body mass index SDS & $0.1(-0.7$ to 0.9$)$ & $-0.1(-0.8$ to 0.5$)$ & 0.37 \\
\hline Pulse wave velocity $(\mathrm{m} / \mathrm{s})$ & $4.7(4.5$ to 4.9$)$ & $4.3(4.1$ to 4.7$)$ & 0.0001 \\
\hline Pulse wave velocity SDS & $0.6(0.0$ to 1.5$)$ & $0.0(-0.7$ to 0.5$)$ & 0.0002 \\
\hline Systolic blood pressure (mmHg) & $107.0(100.7$ to 111.5$)$ & $110.0(100.0$ to 113.0$)$ & 0.64 \\
\hline Systolic blood pressure SDS & $0.2(-0.3$ to 0.6$)$ & $0.2(-0.3$ to 0.6$)$ & 0.91 \\
\hline Diastolic blood pressure $(\mathrm{mmHg})$ & $61.0(58.7$ to 68.0$)$ & $60(60$ to 70$)$ & 0.22 \\
\hline Diastolic blood pressure SDS & $0.0(-0.4$ to 0.4$)$ & $-0.2(-0.7$ to 0.8$)$ & 0.71 \\
\hline $\mathrm{FEV}_{1}(\mathrm{~L})$ & 2.1 (1.6 to 2.6$)$ & Not performed & \\
\hline $\mathrm{FEV}_{1} \mathrm{SDS}$ & $-0.3(-1.5$ to 0.3$)$ & & \\
\hline $\mathrm{FEF}_{25-75}(\mathrm{~L} / \mathrm{s})$ & $2.1(1.7$ to 2.6$)$ & Not performed & \\
\hline $\mathrm{FEF}_{25-75} \mathrm{SDS}$ & $-0.8(-1.5$ to -0.1$)$ & & \\
\hline FeNO (ppb) & $25.1(8.3$ to 44.5$)$ & Not performed & \\
\hline
\end{tabular}

Data are given as median (interquartile range). Pulse wave velocity was measured between the carotid and femoral arteries. The italicized values are highly significant at $P<0.001$

$F E V_{1}$ forced expiratory volume in $1 \mathrm{~s}, F E F_{25-75}$ forced expiratory flow between $25-75 \%$ of expired volume, $F e N O$ fractional exhaled NO 


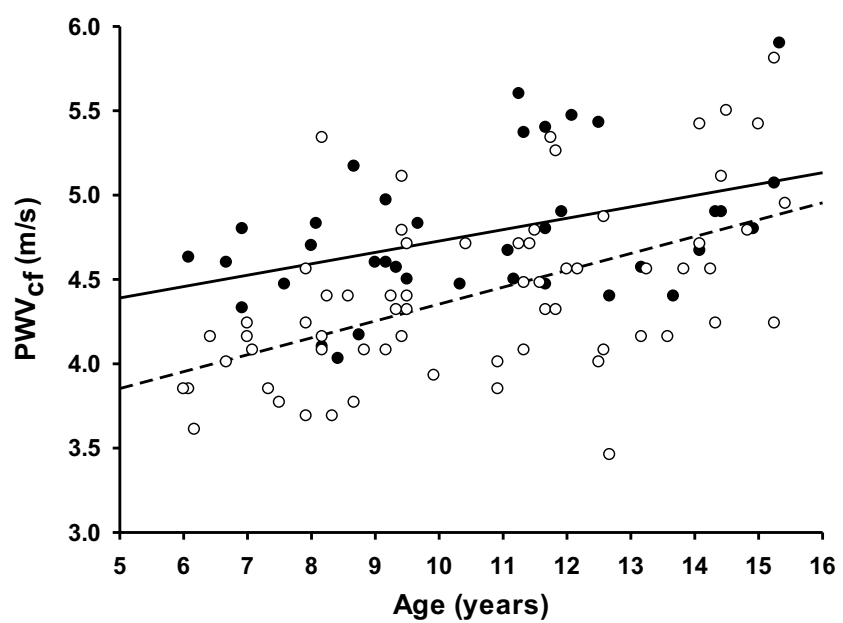

Fig. $1 \mathrm{PWV}_{\text {cf }}$ according to age in asthmatic children (black circles) and in healthy children (control group, white circles). The solid line represents the linear regression line for asthmatic children $\left(r^{2}=0.18, p=0.01\right)$, and the dashed line represents the linear regression line for the control children $\left(r^{2}=0.28, p=0.0001\right)$

cardiovascular system already in childhood and despite asthma control therapy. Furthermore, we observed a weak association of impaired lung function with increased arterial stiffness in asthmatic children, suggesting a relationship between severity of disease and detrimental effects on the cardiovascular system. Arterial stiffness in asthma did not respond to bronchodilator inhalation.

The pathophysiological mechanisms leading to increased arterial stiffness are not fully understood. Recurrent systemic inflammations are believed to trigger structural changes within the vessel wall which on the one hand will pave the way to plaque formation and atherosclerosis and on the other hand will directly translate into increasing arterial stiffness [18]. Eosinophilic airway inflammation estimated by $\mathrm{FeNO}$ was not associated with arterial stiffness in our study. This may be explained in part by the fact that regular usage of inhaled corticosteroids decreases FeNO. We did not assess markers of systemic inflammation or lipoproteins and thus were unable to investigate these mechanisms further. Another possible mechanism present at this early age might be a developmental or genetic basis leading to the association between reduced lung function and increased arterial stiffness and therefore not linked to inflammation. Indeed, a recent study found that reduced lung volume was associated with increased carotid pulse wave augmentation index (a surrogate marker of arterial stiffness) at a very early age, suggesting a developmental link between lung function and arterial stiffness [2], as already postulated by others in adults $[4,14]$.

Our findings extend the relationship between impaired lung function and arterial stiffness from asthmatic adults $[21,24]$ to the pediatric population in which asthma is highly prevalent. Nevertheless, a recent study found opposite results, showing that, in childhood, higher lung function is associated with higher arterial stiffness; this association was mainly explained by anthropometry [9]. These discrepant findings are most likely explained by differences in participants, which were not asthmatic but healthy children and methodology of measurement of arterial stiffness.

A strength of our study is the use of the current gold standard to assess arterial stiffness, with a device validated in a large cohort of healthy control children [11]. Limitations of our study are the relatively small number of asthmatic children which may have influenced subgroup analysis and the inclusion of children with mild-to-moderate asthma only. The study of arterial stiffness in severe asthma or during asthma exacerbations may have strengthened our findings. However, nowadays severe asthma is rarely seen in pediatric patients.

In summary, we found systemic effects of asthma on the cardiovascular function present already in childhood. These findings have important implications for the prevention of cardiovascular disease in asthmatic children and require further study to maintain cardiovascular health in this susceptible population.

Funding The study was funded by the Swiss National Science Foundation (Project PPOOP3_123453 / 1) to Nicolas Regamey.

Conflict of interest None to declare.

\section{References}

1. (2007) Expert Panel Report 3 (EPR-3): Guidelines for the diagnosis and management of asthma-Summary Report 2007. J Allergy Clin Immunol 120:S94-138

2. Ayer JG, Belousova EG, Harmer JA, Toelle B, Celermajer DS, Marks GB (2011) Lung function is associated with arterial stiffness in children. PLoS ONE 6:e26303

3. Bakiler AR, Yavascan O, Harputluoglu N, Kara OD, Aksu N (2007) Evaluation of aortic stiffness in children with chronic renal failure. Pediatr Nephrol 22:1911-1919

4. Bolton CE, Cockcroft JR, Sabit R, Munnery M, McEniery CM, Wilkinson IB, Ebrahim S, Gallacher JE, Shale DJ, Ben-Shlomo Y (2009) Lung function in mid-life compared with later life is a stronger predictor of arterial stiffness in men: the Caerphilly Prospective Study. Int J Epidemiol 38:867-876

5. Cheung YF, Ho MH, Tam SC, Yung TC (2004) Increased high sensitivity $\mathrm{C}$ reactive protein concentrations and increased arterial stiffness in children with a history of Kawasaki disease. Heart 90: $1281-1285$

6. Cole TJ, Green PJ (1992) Smoothing reference centile curves: the LMS method and penalized likelihood. Stat Med 11:1305-1319

7. Doyon A, Schaefer F (2011) Taking the pulse of a sick kidney: arterial stiffness in glomerulonephritis. Pediatr Nephrol 26:161-163

8. Dweik RA, Boggs PB, Erzurum SC, Irvin CG, Leigh MW, Lundberg JO, Olin AC, Plummer AL, Taylor DR (2011) An official ATS clinical practice guideline: interpretation of exhaled nitric oxide levels (FENO) for clinical applications. Am J Respir Crit Care Med 184:602-615 
9. Eising JB, van der Ent CK, Evelein AM, Uiterwaal CS (2014) The association between lung function and arterial stiffness in young childhood. Eur Respir J 44:530-532

10. Fischer DC, Schreiver C, Heimhalt M, Noerenberg A, Haffner D (2012) Pediatric reference values of carotid-femoral pulse wave velocity determined with an oscillometric device. J Hypertens 30 : 2159-2167

11. Kracht D, Shroff R, Baig S, Doyon A, Jacobi C, Zeller R, Querfeld U, Schaefer F, Wuhl E, Schmidt BM, Melk A (2011) Validating a new oscillometric device for aortic pulse wave velocity measurements in children and adolescents. Am J Hypertens 24:12941299

12. Labat C, Temmar M, Nagy E, Bean K, Brink C, Benetos A, Back M (2013) Inflammatory mediators in saliva associated with arterial stiffness and subclinical atherosclerosis. J Hypertens 31:22512258

13. Laurent S, Boutouyrie P, Asmar R, Gautier I, Laloux B, Guize L, Ducimetiere P, Benetos A (2001) Aortic stiffness is an independent predictor of all-cause and cardiovascular mortality in hypertensive patients. Hypertension 37:1236-1241

14. McAllister DA, Maclay JD, Mills NL, Mair G, Miller J, Anderson D, Newby DE, Murchison JT, Macnee W (2007) Arterial stiffness is independently associated with emphysema severity in patients with chronic obstructive pulmonary disease. Am J Respir Crit Care Med 176:1208-1214

15. Stanojevic S, Wade A, Cole TJ, Lum S, Custovic A, Silverman M, Hall GL, Welsh L, Kirkby J, Nystad W, Badier M, Davis S, Turner S, Piccioni P, Vilozni D, Eigen H, Vlachos-Mayer H, Zheng J, Tomalak W, Jones M, Hankinson JL, Stocks J (2009) Spirometry centile charts for young Caucasian children: the Asthma UK Collaborative Initiative. Am J Respir Crit Care Med 180:547-552

16. Stone IS, Barnes NC, Petersen SE (2012) Chronic obstructive pulmonary disease: a modifiable risk factor for cardiovascular disease? Heart 98:1055-1062
17. Strong JP, Malcom GT, McMahan CA, Tracy RE, Newman WP 3rd, Herderick EE, Cornhill JF (1999) Prevalence and extent of atherosclerosis in adolescents and young adults: implications for prevention from the Pathobiological Determinants of Atherosclerosis in Youth Study. JAMA 281:727-735

18. Tousoulis D, Kampoli AM, Papageorgiou N, Androulakis E, Antoniades C, Toutouzas K, Stefanadis C (2011) Pathophysiology of atherosclerosis: the role of inflammation. Curr Pharm Des 17: 4089-4110

19. Urbina EM, Williams RV, Alpert BS, Collins RT, Daniels SR, Hayman L, Jacobson M, Mahoney L, Mietus-Snyder M, Rocchini A, Steinberger J, McCrindle B (2009) Noninvasive assessment of subclinical atherosclerosis in children and adolescents: recommendations for standard assessment for clinical research: a scientific statement from the American Heart Association. Hypertension 54:919-950

20. Van Bortel LM, Laurent S, Boutouyrie P, Chowienczyk P, Cruickshank JK, De Backer T, Filipovsky J, Huybrechts S, Mattace-Raso FU, Protogerou AD, Schillaci G, Segers P, Vermeersch S, Weber T (2012) Expert consensus document on the measurement of aortic stiffness in daily practice using carotidfemoral pulse wave velocity. J Hypertens 30:445-448

21. Weiler Z, Zeldin Y, Magen E, Zamir D, Kidon MI (2010) Pulmonary function correlates with arterial stiffness in asthmatic patients. Respir Med 104:197-203

22. Yildiz M (2010) Arterial distensibility in chronic inflammatory rheumatic disorders. Open Cardiovasc Med J 4:83-88

23. Zanoli L, Cannavo M, Rastelli S, Di Pino L, Monte I, Di Gangi M, Boutouyrie P, Inserra G, Laurent S, Castellino P (2012) Arterial stiffness is increased in patients with inflammatory bowel disease. J Hypertens 30:1775-1781

24. Zureik M, Benetos A, Neukirch C, Courbon D, Bean K, Thomas F, Ducimetiere P (2001) Reduced pulmonary function is associated with central arterial stiffness in men. Am J Respir Crit Care Med 164: 2181-2185 